
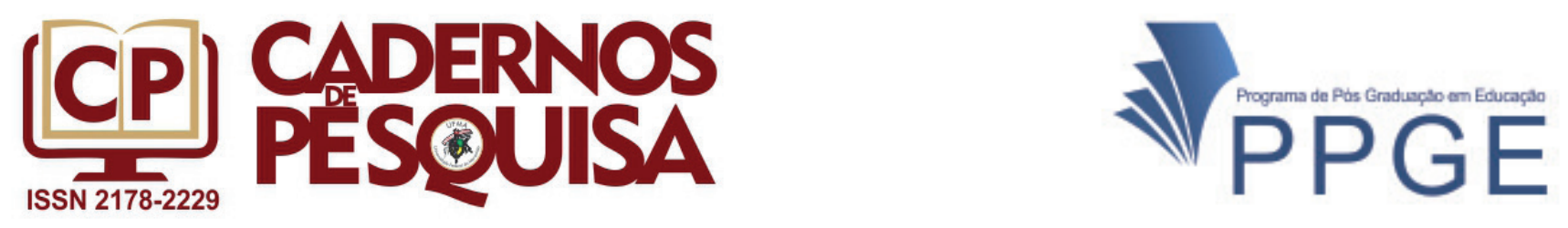

\title{
TORNANDO-SE PROFESSORA: ENTRE A PESQUISA ACADÊMICA E A EDUCAÇÃO BÁSICA
}

\author{
BECOMING A TEACHER: BETWEEN ACADEMIC RESEARCH \\ AND BASIC EDUCATION
}

\author{
CONVIRTIÉNDOSE EN PROFESORA: ENTRE LA \\ INVESTIGACIÓN ACADÉMICA Y LA EDUCACIÓN BÁSICA
}

\author{
Bruna Nunes de Senna Dias \\ https://orcid.org/0000-0002-5787-7693
}

Carmen Teresa Gabriel

https://orcid.org/0000-0001-9503-6740

\begin{abstract}
Resumo: O texto analisa alguns fragmentos narrativos produzidos por uma professora iniciante das séries iniciais da educação básica durante as reuniões do seu grupo de pesquisa do doutorado. Ao tomar como campo empírico tais fragmentos nosso objetivo foi explorar pistas que nos permitam refletir sobre como indivíduos tornam-se professores/as quando estão inseridos simultaneamente em dois contextos cuja articulação tende a ser marcada por relações conflituosas e de subordinação: a escola e a academia. A aposta que fazemos é a de que a experiência de biografização que resultou nessa escrita contribua para se pensar outros caminhos teóricos possíveis para a interface pesquisa científica - docência na educação básica, contribuindo, assim, para desestabilizar binarismos enraizados no campo educacional.
\end{abstract}

Palavras-chave: Professor iniciante. Experiência docente. Narrativas (auto)biográficas. Educação básica. Pesquisa acadêmica.

\begin{abstract}
This text analysis some narratives fragments produced by a beginner teacher of basic education, during her doctoral research team meetings. By the time we set such fragments as empirical field, we intended to exploit traces that allow us to reflect on how individuals become teachers when they are inserted simultaneously into two contexts whose articulation tends to be marked by conflicted and subordinated relations: the school and the university. We defend that the biography's experience, which came out in this written text, contributes to think other theoretical ways to the interface scientific research-teaching in the elementary education, providing, therefore, the destabilization of binarism grounded in the educational field.
\end{abstract}

Keywords: Beginning teacher. Teaching experience. Self-biographical narratives. Basic education. Academic research.

Resumen: El texto analiza algunos fragmentos narrativos producidos por una profesora novel de los primeros grados de la educación básica durante las reuniones de su grupo de investigación de doctorado. Al tomar 
como campo empírico tales fragmentos, nuestro objetivo fue encontrar pistas que nos permitan reflexionar sobre cómo los individuos se convierten en profesores/as cuando están insertos simultáneamente en dos contextos cuya articulación tiende a estar marcada por relaciones conflictivas y de subordinación: la escuela y la academia. La apuesta que hacemos es que la experiencia de biografización que generó el presente trabajo sirva para que se piensen otros caminos teóricos posibles para la interfaz investigación científica - docencia en la educación básica, contribuyendo así a desestabilizar binomios enraizados en el campo educativo.

Palabras clave: Profesor novel. Experiencia docente. Narrativas (auto) biográficas. Educación básica. Investigación académica.

\section{INTRODUÇÃO}

Numa das vezes em que eu estava relatando meus dramas no meu grupo de pesquisa do doutorado, minha orientadora me perguntou como eu estava fazendo para incorporar meus dois anos de estudos sobre currículo, durante o mestrado, na minha nova inserção profissional na escola. Na hora eu só consegui responder que não estava incorporando nada dos meus estudos acadêmicos na minha nova rotina na escola, e que minha atual preocupação era descobrir como explicar a respeito das plantas que comemos. Confesso, porém, que aquela pergunta permaneceu mobilizando meus pensamentos e me fazendo repensar minha prática. (Mestre e doutoranda em Educação, professora iniciante da Educação Básica).

A ideia de construção deste texto surgiu nas reuniões semanais do grupo de pesquisa do qual fazem parte as suas autoras, como orientanda e coordenadora/orientadora. 0 ambiente de investigação está na base, não apenas da ideia do argumento a ser sustentado sobre os processos de identificação docente no início da vida profissional como professores da educação básica, mas da própria possibilidade de sua construção.

A escrita que segue resulta de conversas informais entre uma pesquisadora, formadora de professores/as que há mais de dez anos tem pesquisado e orientado dissertações e teses de doutorado envolvendo a relação entre sujeito e conhecimento em contextos de formação, e uma recém mestra em Educação, pedagoga de formação, atualmente cursando o doutorado, e que no início de 2018 ingressa, pela primeira vez, como professora em uma sala de aula da educação básica, passando a ingressar o quantitativo da categoria "professores iniciantes."

As manhãs de quarta-feira, ao longo dos primeiros meses do calendário escolar de 2018, passaram a ser cadenciadas por relatos que irrompiam, geralmente no início das reuniõesno momento previsto para os "informes", contagiando todo o grupo de doutorandos e mestrandos - em sua maioria professores da educação básica - pautando, muitas vezes, a temática do debate daquele encontro. Ora a escuta voltava-se atentivamente para as narrativas produzidas por acaso, espontaneamente sob a forma de relatos curtos, mas, intensos e em tom de desabafo das experiências vividas em sala de aula que a afetavam, 
a ponto de desestabilizar sua escolha profissional. Ora as reflexões dos demais membros do grupo, incluindo a coordenadora, provocadas pelos depoimentos da colega, ecoavam com mais força, seja para apaziguar as angústias, se solidarizando - do lugar de colegas da mesma profissão - com os desafios e frustações específicas desse ofício, seja para pensar juntos menos soluções do que pistas de interpretação para aquilo que nos era narrado no calor da hora. Nesse segundo movimento sobressaía a fala "experiente desestabilizada" da pesquisadora, coordenadora do grupo em questão, impactada pela narrativa do Outro e buscando também, desesperadamente, criar condições de reflexividade e controlar emoções, transformando-as em objetos de análise e tentando manter o ardor pedagógico da orientanda, convocando para a mesa do debate múltiplos referentes teóricos para auxiliar nessa árdua tarefa de lidar simultaneamente com o sujeito do conhecimento, o sujeito do desejo e o sujeito de demandas.

Nessas conversas ia sendo tecida, sorrateiramente, uma trama - que só mais tarde foi possível significar e nomear como, talvez, um "trabalho de pesquisa-formação" ou um espaço de "mediação biográfica" (PASSEGGI; CUNHA, 2013, p. 44) - permitindo atribuir a um grupo de pesquisa acadêmico sem, a priori, a intencionalidade de se constituir como um espaço de reflexividade da prática docente tampouco, um espaço propício a biografização (DELORY-MOMBERGER, 2012, 2014), uma função dessa natureza. Ao oferecer mecanismos, ainda que informais, para a imersão da narradora-doutoranda-professora iniciante da educação básica no processo de autoria das narrativas de si - naquele contexto e dessa forma - esse grupo assume contingencialmente contornos que extrapolam os sentidos que hegemonicamente lhe têm sido atribuídos, isto é, um local de discussão e desenvolvimento de pesquisas científicas no âmbito universitário, tornando-se assim um espaço entre a pesquisa acadêmica e a sala de aula da educação básica, mas não só.

Esses momentos curtos, intensos e imprevisíveis de troca desestabilizaram e deslocaram também traços de percursos de investigação, reconfigurando o que Mabilon-Bonfils (2017, p. 168, tradução nossa) chama de uma "cenografia da pesquisa que, como tal, põe em movimento processos inconscientes e estratégias valorizando certos aspectos dos procedimentos em detrimento de outros em conformidade à uma retórica do saber e da pesquisa." Afinal, como interpretar a importância atribuída a esses diálogos sem reconhecer os efeitos que os mesmos produziram também na coordenadora-pesquisadora do grupo? Se concordarmos que nenhuma trajetória acadêmica ou itinerário de pesquisa é por acaso e que todo trabalho de investigação apresenta vestígios biográficos, importa sublinhar, igualmente, que essas trocas informais das quartas-feiras estão diretamente relacionadas à singularidade das "raízes subjetivas de uma posição de pesquisador" (GIUST-DESPRAIRIE, 2003, p. 181 apud MABILON-BONFILS, 2017, p. 168, tradução nossa), que imprimem suas marcas tanto nos interesses e objetos de pesquisa como no próprio processo de subjetivação do sujeito-pesquisador.

O nosso interesse em tomar como objeto de reflexão esses momentos vai bem além do que eles podem representar como investimento em um processo de autoconhecimento 
de pesquisadores-professores posicionados em um grupo de pesquisa específico. Apostamos que essa experiência singular pode contribuir para pensar um caminho teórico-metodológico, entre tantos outros possíveis, de articular as atividades de pesquisa científica e de docência, superando visões binárias e dicotômicas que tendem a circular no campo educacional. Do mesmo modo, a reconfiguração desses diálogos como campo empírico de um texto acadêmico em coautoria pode fortalecer o entendimento que

(...) a atividade científica não é nunca assim tão transparente como ela pretende uma espécie de discurso "sem barulho" - ela coloca em jogo muito mais do que os cursos de "métodos das ciências sociais" explicam aos estudantes na clássica descrição sobre como a técnica formata o objeto ou sobre as relações sujeito e objeto. (MABILON-BONFILS, 2017, p. 169, tradução nossa).

Uma escrita, pois, duplamente autobiográfica envolvendo e entrecruzando narrativas de si de sujeitos diferentemente posicionados na cultura profissional docente. Dupla autoriaque traduz, de certa forma, uma maneira de nos relacionarmos com a pesquisa, com o conhecimento, com o mundo e com a escola. Uma "aproximação amorosa" (LARROSA; VENCESLAO, 2017, p. 114), isto é, uma experiência educativa "da qual pudéssemos aprender algo ou na qual ao menos valesse a pena determo-nos por um momento, prestarmos-lhe atenção, deixarmo-nos dizer alguma coisa por ela" (LARROSA; VENCESLAO, 2017, p. 114).

E essa "alguma coisa" sobre a qual queremos falar refere-se justamente a um duplo tensionamento que envolve os desafios que marcam tanto o ingresso de professores iniciantes em sala de aula quanto a relação entre pesquisadores acadêmicos e professores da educação básica. "Alguma coisa" que envolve diretamente processos de subjetivação e de identificação em meio às lutas pela significação da docência, colocando em evidência a importância do entendimento da própria categoria "sujeito" na produção da leitura política do social.

Tanto o argumento como a estruturação da escrita que resultou neste texto podem ser vistos como uma tentativa de sustentar essa afirmação. Mais especificamenteele busca interpretar as experiências de uma professora iniciante das séries iniciais em sala de aula destacando sua dupla inserção como professora da educação básica e também como pesquisadora acadêmica realizando seu curso de doutorado em educação. O objetivo, portanto, deste texto é acessar pistas que indiquem como sujeitos vão se tornando professores, especialmente quando estão inseridos simultaneamente em dois universos de profissionais da educação cuja articulação tende a ser marcada por relações conflituosas e de subordinação.

\section{SOBRE O QUE QUEREMOS FALAR}

Um dos nossos dramas, como diz David Labaree, é que ensinar é uma tarefa de enorme complexidade... mas que parece fácil. Não é. Exige maestria, competência e tacto pedagógico. A organização das situações de aprendizagem, a progressão 
dos alunos ou a concepção de dispositivos de diferenciação pedagógicas são tarefas muito complexas. Ensinar só é fácil para quem nunca entrou numa sala de aula. (NÓVOA, 2004, p. 9).

As questões que dizem respeito à docência se constituem como um objeto de investigação clássico do campo educacional e têm mobilizado uma série de pesquisas de diferentes matrizes teóricas e com múltiplos enfoques. Tendo em vista as condições da produção deste texto, anteriormente mencionadas, interessa-nos mais particularmente aqui dialogar com as contribuições de estudos que, nos debates acadêmicos da área, focalizam tanto os dilemas e desafios enfrentados por esses sujeitos-docentes ao longo de sua trajetória profissional, quanto os efeitos de sua formação inicial e/ou continuada, realizada no âmbito da universidade, nesse processo (HUBERMAN, 1992; NÓVOA, 1992, 1995, 2004, 2017; ZEICHNER, 1998; LAPO; BUENO, 2002; SANTANA, 2016; INGERSOLL; STRONG 2011; GABRIEL, 2015).

O presente texto pretende, pois, entrar nesse debate a partir do entrecruzamento desses dois enfoques. Desse modo, ele busca articular fragmentos autobiográficos de uma professora iniciante-doutoranda na fase da "sobrevivência/descoberta" (HUBERMAN, 1992) em uma sala de aula da educação básica, com as possibilidades de diálogo - que sua condição singular de sujeito permite - com a cultura universitária, mais precisamente com o grupo de pesquisa no qual ela se insere.

As tensões que marcam o ingresso de professores iniciantes na sala de aula vêm sendo exploradas há mais de três décadas pelos estudiosos do campo. Huberman (1992), investigando as etapas da carreira docente, aponta que os três primeiros anos de atuação profissional podem ser compreendidos como um momento de sobrevivência e de descoberta. Para esse autor, "o aspecto da 'sobrevivência' traduz o que se chama vulgarmente de 'choque do real', a confrontação inicial com a complexidade da situação profissional” (HUBERMAN, 1992, p. 39). Nessa fase o professor iniciante está num movimento constante de tatear seu novo espaço profissional, tendo que lidar com as preocupações sobre sua atuação, as complexidades da dinâmica escolar e da sala de aula, a adequação aos conteúdos e materiais didáticos e sua relação com os alunos e colegas de trabalho.

Já o aspecto da "descoberta" é marcado pelo "entusiasmo inicial, a experimentação, a exaltação por estar, finalmente, em situação de responsabilidade (ter a sua sala de aula, os seus alunos o seu programa), por se sentir colega de num determinado corpo profissional" (HUBERMAN, 1992, p. 39). Huberman (1992) destaca que esses dois aspectos, da "sobrevivência" e da "descoberta", são vividos simultaneamente e que são as características da "descoberta" que fazem com que o professor iniciante consiga "sobreviver" profissionalmente.

De modo semelhante, Ingersoll e Strong (2011), ao analisarem o impacto dos programas de indução profissional de professores iniciantes, apontam para alguns desafios que são vivenciados pelos professores iniciantes, como o trabalho mais solitário e isolado dos demais colegas e a colocação em turmas consideradas mais difíceis de trabalhar. As dificul- 
dades que marcam o início da carreira docente se traduzem na alta rotatividade e evasão de professores ainda no seu primeiro ano de carreira profissional. Ingersoll e Strong (2011) apontam para estudos que tem estimado que entre $40 \%$ e $50 \%$ dos professores iniciantes abandonam a carreira docente nos seus primeiros cinco anos de magistério, e que na comparação com outras carreiras profissionais, tais como advogados, enfermeiros, arquitetos, engenheiros e farmacêuticos, os professores da educação básica têm taxas de evasão profissional mais elevadas.

Por outro lado, as pesquisas sobre a docência que focalizam a relação estabelecida entre formação e atuação profissional tendem a evidenciar o fosso entre os aprendizados no âmbito dos cursos de licenciatura e as exigências, de todas as ordens, do exercício profissional na educação básica. Kenneth Zeichner (1998, p. 207), em texto que aborda "questões de poder, privilégio, voz e status na pesquisa educacional, e a necessidade de eliminar a separação que atualmente existe entre o mundo dos professores-pesquisadores e o mundo dos pesquisadores acadêmicos", aponta para as tensões que marcam esses dois grupos de profissionais dedicados à educação. O autor destaca que, se por um lado os professores não veem utilidade nas pesquisas acadêmicas para satisfazer suas demandas formuladas na/da escola, por outro lado os pesquisadores acadêmicos rejeitam a pesquisa produzida pelos professores e não a reconhecem como produção de conhecimento. Zeichner (1998, p. 217) chega a afirmar que o mundo dos pesquisadores acadêmicos e dos professores "raramente se cruzam."

Os aspectos controversos que marcam essa relação também foram sinalizados por Gabriel (2015) ao afirmar que a docência ocupa lugar subalternizado e desvalorizado na comparação com outros profissionais que lidam com o conhecimento, tais como os pesquisadores nas universidades. Uma vez que os professores não são reconhecidos, na maioria das vezes, como produtores de conhecimento, mas apenas como aqueles que aplicam os conhecimentos desenvolvidos pela comunidade acadêmica através da pesquisa científica, eles, os professores, se veem desvalorizados no exercício de sua atividade profissional.

\footnotetext{
No que diz respeito à docência e considerando a estruturação desigual, hierárquica e excludente do sistema de conhecimento hegemonizada no sistema escolar, é possível afirmar que esta tem ocupado uma posição de subalternidade. Historicamente identificada como um ofício sem saberes, a docência tende a ser vista como um "lugar menor", de menos prestígio quando comparada a outras posições que se relacionam igualmente com o conhecimento científico como, por exemplo, a pesquisa. (GABRIEL, 2015, p. 436).
}

Ao mobilizar, de forma articulada, discursos que evidenciam tanto os desafios que marcam o ingresso na carreira docente quanto as tensões que marcam a relação entre pesquisadores acadêmicos e professores da educação básica - a escrita deste texto filia-se à produção da área que tem buscado explorar pistas teóricas-metodológicas para que as experiências de uma professora iniciante, que vive os dilemas do ingresso na carreira do- 
cente em concomitância com o desenvolvimento de sua formação acadêmica em curso de doutorado em educação, sejam tomados como objeto de análise e de reflexão.

\section{PERSPECTIVAS ARMADAS PARA VER ESSA “ALGUMA COISA” SOBRE A QUAL QUEREMOS FALAR}

Talvez a morte do Sujeito (com S maiúsculo) tenha sido a principal precondição para esse renovado interesse na questão da subjetividade. Talvez seja a própria impossibilidade de se remeterem as expressões concretas e finitas de uma subjetividade multifacética a um centro transcendente que permita concentrarmos nossa atenção sobre a multiplicidade em si. (LACLAU, 2011, p. 47).

As reflexões desenvolvidas neste texto se inscrevem em um movimento teórico mais amplo envolvendo o entendimento da subjetividade e seus efeitos nesse presente que nos é contemporâneo. Como aponta Laclau (2011), na citação acima, a questão da subjetividade não pode estar desconectada do debate epistemológico atual no âmbito das ciências sociais, marcado pelo reconhecimento da potencialidade analítica da incorporação, na leitura política do social, da dimensão ontológica, até data relativamente recente confinada ao domínio da filosofia (MARCHART, 2009; RETAMOZO, 2012). Com efeito, a emergência de abordagens adjetivadas como pós-fundacionais, as quais nosso grupo de pesquisa se filia, oferecem ferramentas para pensarmos essa questão de um outro lugar epistêmico.

A radicalização da crítica às interpretações essencialistas implica na negação da existência de fundamentos metafísicos e últimos na compreensão do social, afirmando a função instituinte da linguagem no acesso ao mundo no qual vivemos, agimos e sobre o qual produzimos conhecimento. Trata-se de uma postura epistêmica que provoca o que tem sido chamado de uma "virada ontológica", questionando a ênfase atribuída a algumas figuras da modernidade que assumem o lugar de um centro transcendente, como por exemplo, os significantes Razão, Sujeito ou Ciência.

Nos limites deste texto não cabe nos aprofundarmos sobre os aportes teóricos dessas abordagens discursivas. Nos propomos, assim, a sublinhar apenas seus efeitos para pensar os processos de subjetivação/identificação, em particular quando mobilizados no campo da estruturação da docência e da pesquisa. Para Laclau (2011, p. 47) é justamente o reconhecimento da morte desse sujeito moderno que possibilitou "um novo e difundido interesse nas múltiplas identidades que estão emergindo e proliferando no mundo contemporâneo."

O pós-fundacionalismo (MARCHART, 2009), que tem nos oferecido uma caixa de ferramenta para, não apenas, pensarmos nossos objetos de pesquisa, mas também, e sobretudo, produzirmos análises políticas da realidade social/educacional, se caracteriza como uma abordagem teórica que radicaliza a crítica às posturas baseadas em interpretações essencialistas e deterministas. Essa postura epistêmica é frequentemente criticada por aqueles que a interpretam como uma postura despolitizada, uma vez que abre mão de 
certezas e projetos de sociedade definitivos previamente definidos (LOPES, 2013). Contudo, o fato dessa teorização defender que toda significação é um ato contingencial de poder, resultante de uma articulação particular e provisória em meio à uma infinidade de possibilidades, permite que o espaço de luta seja expandido e abre a oportunidade de "deslocar a fronteira, investir na produção de outros universais, de outros antagonismos, em meio a novas práticas articulatórias diferentes das até hoje hegemônicas" (GABRIEL, 2013, p. 49).

Nessa perspectiva, o fechamento provisório e contingencial que produz uma ordem social mobiliza processos de identificação, igualmente, provisórios e contingenciais. Uma vez que reconhecemos que toda realidade é construída discursivamente, ou seja, que ela se constituí como tal mediante a produção de uma determinada narrativa que construímos sobre ela, não existindo nenhuma ordem social pré-estruturada com base em fixações essencialistas ou deterministas, também não podemos considerar a existência de identidades fixas ou baseadas em algum tipo de essência metafísica. Afinal como afirma Laclau (2011, p. 48-49):

\begin{abstract}
Assim desaparecido o objetivismo como "obstáculo epistemológico", tornou-se possível desenvolver todas as implicações da "morte do sujeito". Nesse ponto, esta última mostrou o veneno oculto que a habitava a possibilidade de sua segunda morte: a morte da morte do sujeito; a emergência do sujeito em decorrência de sua própria morte ; a proliferação de finitudes concretas cujas limitações são a origem de sua força; o reconhecimento de que pode haver "sujeitos" porque o vazio que "o Sujeito" deveria preencher é na verdade, irreparável.
\end{abstract}

Ao desconstruirmos a ideia de uma estrutura absoluta também desconstruímos a noção de sujeitos com identidades absolutas. Nenhuma identidade, do ponto de vista ontológico, pode ser determinada por qualquer estrutura porque esta não existe como um todo estruturado. Desse modo, as identidades não estão definitivamente fixadas, mas se caracterizam por estarem em constante movimento. "Algumas entram em crise, colapsam, outras surgem ou ressurgem renegociadas" (LOPES; MACEDO, 2011, p. 218).

Reconhecemos, pois, que, longe de despolitizar as disputas em torno da formação de professores, a abordagem epistêmica pós-fundacional nos ajuda a desessencializar os processos de identificação docente hegemonizados pelo senso comum e, muitas vezes, incorporados pelo próprio campo educacional. Ao oferecer ferramentas de análise para a compreensão dos mecanismos de negociação e disputas que constituem estes processos, essa abordagem abre espaço para outras formas de leitura política da realidade social/ educacional e outras apostas de sentido de docência que nos auxiliam no enfrentamento teórico dos desafios que marcam o ingresso na carreira docente. O reconhecimento de que tanto a ordem social quanto os processos de identificação são fechamentos sempre provisórios e contingentes permite que entremos na luta política por sua significação, uma vez que as fronteiras de delimitação do significado estão sempre abertas. 
Nesse mesmo movimento teórico se inscreve a crítica que Biesta (2013) faz ao humanismo e a concepção de educação moderna centrada na ideia da existência de uma essência da natureza humana que seria alcançada através do processo educativo. Contrapondo-se a essa ideia Biesta (2013, p. 19, grifo do autor) propõe que

(...) tratássemos a questão do que significa ser humano como uma questão radicalmente aberta, uma questão que só podemos responder participando da educação, em vez de uma questão que precisamos responder antes de poder participar da educação.

Ao sublinhar a crise do humanismo e a "morte do sujeito" autônomo, desenhado pela modernidade, esse autor nos lembra que essa "morte do sujeito" não representa o fim da humanidade, "mas apenas o fim de uma determinada articulação moderna da subjetividade humana" (BIESTA, 2013, p. 62, grifo do autor). O fim de um tipo particular de subjetividade, não implica a busca de uma outra para substituí-la, mas sim, o reconhecimento que nenhuma teoria/explicação a priori do sujeito pode ser formulada.

A questão que se coloca no lugar daquela sobre "o que é o ser humano" é a "questão de onde o sujeito, como um ser único e singular, torna-se presença" (BIESTA, 2013, p. 65). Esta, portanto, "não é uma questão de essência, mas de identidade" (NANCY, 1991, p. 7 apud BIESTA, 2013, p. 66). O sujeito moderno nunca foi pensado nos termos de "quem", mas sim como "o que", tal qual uma coisa. "Enquanto a questão sobre o que é o sujeito pede uma definição do sujeito em geral, a questão sobre quem é o sujeito pede uma identificação do que poderíamos chamar o ser do sujeito como um indivíduo singular" (BIESTA, 2013, p. 66, grifo do autor).

Para Biesta (2013) "tornar-se presença" é mais do que se apresentar ao mundo, mas "consiste em começar num mundo cheio de outros iniciadores, de tal maneira que não sejam obstruídos as oportunidades para que outros iniciem" (BIESTA, 2011, p. 75). É, portanto, dentro da estruturação discursiva da ordem social que os sujeitos se posicionam buscando dar sentido às suas experiências. "As identidades nomeadas talvez pudessem ser mais bem descritas como fixações de identificações contingentes dos sujeitos, que ocorrem em circunstâncias muito próprias" (LOPES; MACEDO, 2011, p. 224).

É justamente nessa perspectiva que este texto foi construído, como enunciado na sua introdução. Resultante de conversas não planejadas entre sujeitos fixados narrativamente e contingencialmente como pesquisadora-coordenadora e professora da educação básica-doutoranda, no contexto específico de um grupo de pesquisa, esta escrita incorpora elementos do gênero biográfico, afirmando o entendimento das "narrativas de si" como processos de produção de subjetividades. Em consonância com a perspectiva teórica pós-fundacional a abordagem biográfica é aqui assumida como uma postura investigativa potente para pensarmos os processos de identificação dos sujeitos.

Mas, que discursos sobre processos de subjetivação/identificação o uso do adjetivo biográfico permite reforçar e/ou deslocar? Estudos biográficos recentes (DELORY-MOM- 
BERGER, 2012, 2014) apontam a emergência do sujeito biográfico como resultante de processos de hegemonização de narrativas particulares que operam com o entendimento de subjetivação como processos inacabados, simultaneamente simbólicos, políticos e contingenciais. Assim, como vimos trabalhando em nossas pesquisas, a narrativa (auto)biográfica outorga aos sujeitos "o lugar de protagonistas de suas vidas, transformando acontecimentos, indivíduos e atitudes em episódios, intrigas e personagens"(DELORY-MOMBERGER, 2011, p. 341). Neste sentido, a narrativa se apresenta não apenas como a forma por meio do qual os sujeitos expressam o sentimento de suas existências, mas o espaço em que 0 ser humano elabora e experimenta a sua história de vida. A biografia é, portanto, para Delory- Momberger (2011, p. 342):

(...) uma dimensão do agir humano que permite aos indivíduos, dentro das condições de suas inserções sócio-históricas, integrar, estruturar, interpretar as situações e os acontecimentos vividos. Tal atividade de biografização apresenta-se como uma hermenêutica prática, um marco de estruturação e de significação da experiência que permite ao indivíduo criar uma história e uma forma própria - uma identidade ou individualidade - para si mesmo.

Ao reconhecer que falar da construção da experiência é falar da maneira como cada um de nós vive, conhece e experimenta o mundo (DELORY-MOMBERGER, 2016), esse enfoque permite entrever uma maneira de escrever ou falar de experiência, sem essencializá-la. Afinal, como os estudos feministas já vêm nos provocando a pensar há mais de duas décadas

\begin{abstract}
Não são os indivíduos que tem experiência, mas os sujeitos é que são constituídos através da experiência. A experiência, de acordo com essa definição, torna-se, não a origem de nossa explicação, não a evidência autorizada (porque vista ou sentida) que fundamenta o conhecimento, mas aquilo que buscamos explicar, aquilo sobre a qual se produz conhecimento. (SCOTT, 1999, p. 5).
\end{abstract}

Operamos, pois, com o sentido de narrativa biográfica como discurso que não apenas relata, mas cria ontologicamente o sujeito. Ao produzir uma síntese do heterogêneo, entre passado, presente e futuro, as narrativas, assim entendidas, permitem dar sentido e forma às experiências vividas. Para Delory-Momberger (2014) a atividade biográfica se traduz como uma atividade constante de construção singular das situações que vivemos, fazendo de uma situação vivida uma experiência própria. Para a autora ao darmos sentido e forma às experiências vividas estamos constantemente biografando o que vivemos. "Para dar uma definição geral, chamo biografização o conjunto de operações e comportamentos por meio dos quais os indivíduos trabalham para dar-se uma forma própria na qual se reconhecem a si mesmos e se fazem conhecer pelos outros" (DELORY-MOMBERGER, 2014, p. 699 , tradução nossa). 
A abordagem biográfica - que se traduz em uma postura epistemológica de fazer pesquisa - ao invés de se interessar em buscar a essência do ser humano ou de tentar desvendar qual seria o núcleo central que definiria a identidade do sujeito está preocupada em investigar os "modos de constituição do indivíduo enquanto ser social e singular" (DELORY-MOMBERGER, 2012, p. 524). A singularidade da pesquisa biográfica é, então, o reconhecimento de que a experiência está inserida dentro de um tempo específico da vida de cada indivíduo. "A postura específica da pesquisa biográfica é mostrar como a inscrição forçosamente singular da experiência individual em um tempo biográfico se situa na origem de uma percepção e de uma elaboração peculiar dos espaços da vida social" (DELORY-MOMBERGER, 2012, p. 524).

Assim, o que nos anima a investir nessa perspectiva epistemológica de fazer pesquisa é a possibilidade de compreender como os sujeitos singulares biografizam suas experiências a partir do que Capriati (2016) nomeia de "giros da existência", isto é, "um momento vital identificado pelo sujeito-narrador e/ou pelo sujeito-investigador - como uma encruziIhada a partir da qual o itinerário biográfico da pessoa toma um rumo distinto, ou se inicia uma nova etapa" (CAPRIATI, 2016, p. 223, tradução nossa).

A seguir organizamos o texto com o propósito de colocar em evidência três momentos identificados nas conversas do grupo de pesquisa como potencialmente exercendo essa função discursiva de "pontos de virada" nas trajetórias entrecruzadas de sujeitos posicionados como pesquisadores e professores da educação básica. Afinal, como nos apontam Ramos e Gonçalves (1996), no tocante às experiências dos professores vividas em sala de aula, a narrativa é uma tentativa de ordenar, compreender, adaptar e atuar sobre as experiências que atravessam a sala de aula cujos contornos se deixam ver em meio a contingências, imprevisibilidades e complexidades.

\section{CENAS DE "GIROS DE EXISTÊNCIA” NAS NARRATIVAS PRODUZIDAS EM UM GRUPO DE PESQUISA}

Nesta seção, trazemos fragmentos de alguns relatos e diálogos que se deram no âmbito do grupo de pesquisa ao qual a professora iniciante está inserida. Apresentaremos esses relatos tomando-os como "cenas" do processo dessa professora em reconhecer-se como parte do grupo profissional docente, entendendo que cada um desses relatos são experiências do momento da entrada na carreira vividos como "giros de existência" no seu processo de identificação docente.

\section{CENA 1 - "SOU A NOVA PROFESSORA!"}

Essa semana eu precisei abrir a conta no banco para receber o salário da escola. Quando o gerente do banco perguntou qual era minha profissão fiquei alguns segundos procurando as palavras até conseguir dizer: "Sou professora!". Depois 
aconteceu uma situação parecida. Quando eu cheguei na escola, no meu primeiro dia, o guarda na portaria me perguntou quem eu era, para poder liberar minha entrada. Eu também precisei de alguns segundos até conseguir dizer: "Sou a nova professora!" (Professora Iniciante).

Para entendermos porque a professora iniciante em questão se surpreendeu com sua necessidade de ter que elaborar as palavras até conseguir formular a resposta "eu sou a nova professora" é preciso voltarmosa alguns aspectos de sua trajetória de formação. No ano de 2015 ela concluiu o curso de Pedagogia. Contudo, a escolha pela Pedagogia se deu após ela já ter cursado um ano e meio da faculdade de História, tendo decidido mudar de carreira pois não estava satisfeita nem com o curso nem com a possível colocação profissional que esse curso iria lhe possibilitar no futuro como historiadora. Marcada por algumas experiências que a aproximavam da atuação como professora optou por trocar de curso.

De acordo com seu relato dois fatores marcaram profundamente sua escolha pela Pedagogia. O primeiro foi o intenso envolvimento com atividades educativas voluntárias que desempenhava na época, dando aula de religião uma vez por semana para um grupo de crianças. O segundo fator foi uma disciplina eletiva chamada Psicologia do Desenvolvimento Infantil, cursada ainda durante a graduação em História, onde lhe foram apresentadas as proposições teóricas de Lev Vygotsky juntamente com a reflexão sobre a importância da interação com o outro para o desenvolvimento dos sujeitos e a compreensão do professor como um mediador da aprendizagem e sua importância para o desenvolvimento das crianças. A partir dessas duas experiências marcantes, e descontente com o curso de História, a professora em questão mudou de curso, saiu da universidade pública que até então estudava e se matriculou em uma universidade particular para cursar Pedagogia.

Ao longo de suas falas e compartilhamentos com os membros de seu grupo de pesquisa, sobre os motivos de sua mudança para a Pedagogia, a professora iniciante sempre destacou que sua escolha foi mobilizada por articulações estreitamente ligadas ao ensino de crianças, a ação em sala de aula e a uma identificação pessoal que despertava nela o desejo de ser professora. No entanto, ficava evidente em seus depoimentos seu ressentimento ou decepção quanto ao currículo do curso de Pedagogia na nova universidade. Apesar de oferecer disciplinas voltadas para a formação de professores, o currículo tinha, segundo o relato, uma carga horária ampliada de matérias vinculadas aos cursos da área de administração, de sorte que sentiu falta de maior aprofundamento em disciplinas que a formassem para "ser professora" e para atuar dentro da sala de aula no processo de ensino-aprendizagem com os alunos.

A constatação dessa professora iniciante, até então professora em formação, de que faltava no curso de Pedagogia uma formação mais específica para atuação como professora da educação básica vai ao encontro de pesquisas que tem apontado para uma fragilidade na articulação entre a formação de professores e a pluralidade de identidades formativas que são investidas no currículo de Pedagogia, que nem sempre dizem respeito 
à atuação futura como professor da educação básica (GATTI; BARRETO, 2009; LIBÂNEO, 2013; PUGAS, 2013; PIMENTA et al., 2017; SENNA DIAS, 2018).

Com base em dados de uma pesquisa que buscou investigar 25 cursos de Pedagogia no Estado de Goiás Libâneo (2013) afirma que o que se percebe na análise das grades curriculares e ementas das disciplinas desses cursos é uma desvalorização da formação específica do professor. Com efeito,

a análise dos dados mostrou que a proporção de horas/aula destinada ao bloco "formação profissional específica" correspondeu a $28,2 \%$ (em média), ou seja, um terço da carga horária total dos cursos, informação que nos parece expressiva para indicar a desvalorização da formação profissional específica do professor. (LIBÂNEO, 2013, p. 81).

O resultado da pesquisa aponta justamente para a ausência, nos currículos de Pedagogia, dos conteúdos que serão ensinados nos anos iniciais do ensino fundamental, como se houvesse "um entendimento tácito entre os professores-formadores e entre os coordenadores de cursos responsáveis pelo currículo de que os alunos já dominam esses conteúdos, trazidos do ensino médio, o que, como se sabe, não acontece" (LIBÂNEO, 2013, p. 83). A conclusão que Libâneo (2013, p. 88) chega é que existem "graves lacunas nesses cursos, com prováveis efeitos danosos para a formação de professores para a educação infantil e anos iniciais do ensino fundamental."

Pimenta et al. (2017) também analisam matrizes curriculares dos cursos de Pedagogia, mas em cursos no Estado de São Paulo. Os autores apontam para uma multiplicidade e variedade de disciplinas nos cursos sendo "muitas delas sem aderência à docência e às questões próprias dos anos iniciais da educação básica. O que sugere um perfil amplo, disperso e impreciso do egresso dos cursos analisados" (PIMENTA et al., 2017, p. 32). Para Pimenta et al. (2017, p. 35) a ampla possibilidade de atuação do pedagogo marca uma formação difusa e dispersa, "o que acaba por inviabilizar uma sólida formação de professor polivalente para os Anos Iniciais do Ensino Fundamental e da Educação Infantil."

Os resultados dessas pesquisas, embora apontem para situações atuais desses cursos, podem ser vistas como pontas de fios de uma meada que foi sendo tecida ao longo da trajetória de constituição do curso de Pedagogia no Brasil. Se hoje este curso tem como objetivo expresso por lei, desde 2006, formar professores para a Educação Infantil e Anos Iniciais do Ensino Fundamental, essa nem sempre foi sua função. Com efeito, até que se chegasse a essa finalidade específica, o curso de Pedagogia teve sua trajetória marcada pela formação de bacharéis para exercerem funções de técnicos em educação e, posteriormente, especialistas em educação nas áreas de supervisão, administração, planejamento, orientação e inspeção educacional. Quando, após a publicação da Lei de Diretrizes e Bases da Educação Nacional no 9.394/1996, foi estabelecido que a formação dos professores da educação básica deveria ser feita em nível superior o curso de Pedagogia foi escolhido 
como a licenciatura que formaria os professores destinados a atuar nas primeiras experiências escolares das crianças.

Segundo Silvestre e Pinto (2017, p. 18) as novas Diretrizes Curriculares para o curso de Pedagogia "buscaram conciliar sua tradição histórica (Bacharelado) com as novas demandas (Licenciatura)." Silva Júnior (2017, p. 8) destaca que as novas diretrizes curriculares atenderam "às proposições hegemônicas da época", das quais se destacam a elevação da formação dos professores de todas as etapas da educação básica para o ensino e a defesa da docência como base da formação de todo profissional da educação (AGUIAR et al., 2006; SILVA, 2006; CRUZ, 2011; CRUZ; AROSA, 2014; FRANCO, 2012; LIBÂNEO, 2006, 2013; SAVIANI, 2008; SCHEIBE; DURLI, 2011). Contudo, apesar da hegemonização dessas ideias Silva Júnior (2017, p. 8) destaca que:

Para que outras proposições e outros entendimentos pudessem também ser contemplados, estendeu as possibilidades de ação [dentro da formação em Pedagogia] para mais de uma licenciatura e acolheu ainda uma extensa variedade de perspectivas de trabalho pedagógico que transcendia os limites das instituições escolares.

Essa dispersão do foco relacionado ao perfil do profissional da educação que este curso se propõe a formar - traduzida pela ambivalência das proposições formativas que ora enfatizam a formação de professores dos anos iniciais, ora abarcam funções e ações quetranscendem os limites as instituições escolares - pode ser vista como um dos indicativos pelos quais a professora iniciante tenha precisado de um tempo para poder efetivamente se reconhecer como professora e, então, poder sustentar o enunciado: "eu sou a nova professora!". Durante seus relatos, compartilhados no grupo de pesquisa, ela expressou que mesmo já formada pedagoga e podendo, portanto, atuar como professora, não se identificava como tal. Para ela faltava a experiência da sala de aula para que pudesse assumir sua identidade profissional como professora.

Seguindo a trilha das experiências que marcaram seu processo de subjetivação docente e seu auto reconhecimento como "sujeito posicionado como professora" destacamos que ela, após concluir a graduação em Pedagogia, foi convocada para tomar posse como professora efetiva do município do Rio de Janeiro. No entanto, no mesmo dia que saiu sua nomeação como professora foi informada de que havia sido selecionada para iniciar seu mestrado em educação. Ao narrar informalmente esse episódio para os colegas nas rodas de conversas do seu grupo de pesquisa a professora iniciante o significou, no âmbito daquele contexto específico, como uma situação de tomada de decisão entre ser professora ou fazer o mestrado e reingressar na vida acadêmica, pois, como ela destacou algumas vezes, não se reconhecia apta a ter que lidar com as demandas do ingresso na vida profissional docente numa jornada de trabalho de $40 \mathrm{~h}$ semanais e de, ao mesmo tempo, investir em sua formação acadêmica no mestrado. A opção pelo mestrado, ainda segundo seu próprio relato, a obrigou a adiar seu ingresso na carreira docente. 
Durante os dois anos do mestrado ela conta que quando perguntavam qual era sua profissão sua resposta era: "sou formada em Pedagogia", sem assumir ainda uma identidade docente ou reconhecer-se como professora. Nas últimas semanas antes da sua defesa da dissertação de mestrado, e prestes a ingressar no doutorado em educação, foi convocada como professora substituta dos anos iniciais de um colégio público federal. Dessa vez ela não abriu mão de iniciar sua carreira docente e, concomitantemente com seu ingresso no doutorado, deu início à sua primeira experiência como professora da educação básica em uma turma de $2^{\circ}$ ano do ensino fundamental com alunos de 7 anos de idade. Foi a partir desse momento que ela passou a dizer "eu sou a nova professora!"

\section{CENA 2 - "NA VERDADE EU NÃO SEI NEM POR ONDE COMEÇAR."}

Eu estou muito perdida, não sei nem por onde começar. Que materiais usar? Qual conteúdo que eu tenho que dar? É como se todos os dias eu tivesse que inventar a roda e descobrir sozinha o que ensinar e como ensinar. Nem sei se é isso que eu deveria estar fazendo e por quanto tempo mesmo eu vou querer ser professora. Agora tenho que pensar em avaliação e nem sei como fazer isso. Tem um mês só que eu estou com essas crianças, como que eu vou avaliar elas se nem conheço elas direito? Essa semana mesmo aconteceu uma coisa interessante... eu levei a imagem do Franjinha, aquele cientista da turma da Mônica, para as crianças colorirem e colarem na capa do caderno de ciências. Aí um aluno meu que é negro perguntou se podia pintar o Franjinha igual a ele, com a pele e cabelo escuros, porque ele queria ser cientista quando crescesse. Eu disse que podia, claro! Mas aí outro aluno meu que é loiro, bem parecido com o Franjinha até, foi e pintou o desenho igual a ele, branco e loiro, e veio me dizer assim: "olha tia, eu pintei o Franjinha como ele é na vida real". Mas eu sabia que ele estava fazendo isso pra atacar o colega que pintou o Franjinha negro. Aí na hora eu virei para o menino que tinha pintado o Franjinha "igual ele era na vida real" e disse assim: "Em primeiro lugar não existe Franjinha na vida real, porque o Franjinha é só um desenho, e em segundo lugar, desenho cada um pinta como quiser!" (Professora Iniciante).

Mas você falou isso com as crianças? Disse que o Franjinha não existia? Desconstruiu o imaginário infantil? (Risos). (Orientadora do Grupo de Pesquisa).

Eu disse! Eu sabia o que estava acontecendo ali, ele estava querendo atacar o menino que pintou o Franjinha negro dizendo que o Franjinha loiro que era o "de verdade". Não desconstruí nada não. O Franjinha não existe mesmo! (Professora Iniciante).

Aí, está vendo só! Você conhece seus alunos! Está aí falando que não conhece, que não sabe como avaliar, mas você conhece sim, tanto que avaliou essa situação aí do Franjinha. (Colega do grupo de pesquisa).

Mas me diz como você tem feito para incorporar esses seus dois anos de estudos sobre o currículo durante o mestrado nas suas aulas na escola? Como que seu 
tempo e investimento de pesquisa durante o mestrado estão te ajudando agora na sala de aula? (Orientadora do Grupo de Pesquisa).

Olha, sinceramente, não estou incorporando nada, na verdade eu não sei nem por onde começar. Nesse momento, para dizer a verdade, eu estou preocupada é em ensinar sobre as plantas que comemos nas aulas de ciências. (Professora Iniciante).

Como indicado no diálogo que abre essa segunda cena as dificuldades que marcaram o ingresso na carreira docente da professora iniciante não foram apenas no sentido de se identificar como tal para o gerente do banco ou para o porteiro da escola. Ao narrar suas experiências de entrada na sala de aula pela primeira vez e se deparar com aquelas crianças que, como ela conta, estavam cheias de expectativas para conhecer a nova professora, uma infinidade de perguntas pairou sobre sua cabeça: "o que eu estou fazendo aqui? O que eu vou ensinar para essas crianças? Será que eu vou dar conta dessa responsabilidade?". Essas e outras perguntas a faziam constantemente questionar o seu lugar como professora e a trazer para o seu grupo de pesquisa relatos como o descrito acima, que propiciavam uma troca entre seus membros e oportunizava que aquele espaço, até então fortemente marcado por uma preocupação mais voltada para a investigação acadêmica em educação, se tornasse também um espaço de biografização e de compartilhamento e construção de processos de subjetivação/identificação docente.

As articulações, por vezes conflituosas, que marcam as relações entre pesquisadores acadêmicos e professores da educação básica, e já sinalizadas neste texto (ZEICHNER, 1998; GABRIEL, 2015), podem também ser vislumbradas nessa narrativa da professora iniciante. Imersa nos dilemas e complexidades de se adequar ao seu novo lugar profissional como professora ela afirma que suas preocupações sobre o que fazer em sala de aula não podiam ser solucionadas ou diminuídas acessando seu repertório de conhecimento e a bagagem acadêmica acumulada ao longo dos seus estudos de mestrado. Durante seus momentos de desabafo sobre a profissão ela sinalizava que suas preocupações eram mais "práticas" e que o que ela queria saber era "como que eu vou ensinar unidade e dezena para os meus alunos? Ou o que ensinar sobre as plantas que comemos? Por onde eu começo?". Sua fala, por vezes, era marcada por certa frustração de alguém que dizia que há muito tempo desejava "ser professora", mas que agora não tinha mais tanta convicção de sua capacidade em ocupar esse lugar. Em contrapartida, ela também se questionava sobre seu lugar enquanto pesquisadora acadêmica-doutoranda em educação, e não foram poucas as vezes em que dizia: "não dei conta das leituras essa semana", ou "essa semana faltei todas as aulas do doutorado porque estava muito cansada pelo trabalho na escola", ou ainda "não sei nem o que eu estou fazendo aqui nesse doutorado, como isso me ajuda amanhã na escola com as crianças?"

Se por um lado o ingresso na carreira docente já traz suas complexidades, seja pela adequação as demandas e rotina escolar, seja pelas lacunas deixadas pela formação inicial, ou pelo tempo de ajuste e entrosamento com a equipe de trabalho e os alunos, por 
outro, a dupla inserção como professora iniciante e pesquisadora-acadêmica pode levantar novas questões que trazem a tona as articulações assimétricas entre escola e universidade. Nóvoa (2017, p. 1109) aponta que nos últimos anos têm crescido uma insatisfação com a distância entre o universo escolar e a universidade, "como se houvesse um fosso intransponível entre a universidade e as escolas, como se a nossa elaboração académica pouco tivesse contribuído para transformar a condição socioprofissional dos professores." Ao tratar dessa distância, entre a universidade e a escola, Nóvoa (2017) faz referência a um processo de desprofissionalização da carreira docente no qual estão imersos os professores, seja pela desvalorização e precarização do seu trabalho ou pelo crescimento de uma visão crítica e negativa das universidades enquanto instituições de formação de professores.

O relato da professora iniciante que diz que "não sei por onde começar" e que suas preocupações mais "práticas" sobre o que fazer em sala de aula não podem ser resolvidas por seus estudos acadêmicos sobre currículo podem ser um indicio potente desse fosso entre a universidade e a escola. Contudo, como veremos na cena a seguir, é mediante a provocação, feita pela sua orientadora, sobre sua eventual incorporação dos estudos acadêmicos em suas aulas na educação básica que ela reelabora suas preocupações "práticas" e formula uma atividade para sua turma.

\section{CENA 3 - "QUERIDA PROFESSORA, TE AMO! SEJA UMA BOA CIENTISTA!"}

Aquela conversa da semana passada, sobre como eu estava incorporando meus estudos sobre currículo ao longo do mestrado nas minhas aulas com as crianças, ficou "martelando" na minha cabeça desde aquele dia. Fiquei pensando que realmente depois de dois anos estudando tanto isso tinha que fazer alguma diferença na minha prática em sala de aula. (Professora Iniciante).

E quais foram as reflexões sobre a sua prática que nossa conversa gerou? (Orientadora do Grupo de Pesquisa).

Essa semana eu fui dar uma aula de ciências que abordava as características de um cientista. Aí a pergunta da semana passada ficou aqui na minha cabeça... Então pensando nisso decidi que iria apresentar para meus alunos uma concepção de cientista que não se limitava apenas ao estereótipo de alguém de jaleco branco dentro de um laboratório mexendo com elementos químicos, microscópios e pipetas. Decidi que iria mostrar para eles que cientista é quem se dedica a fazer pesquisa, a produzir conhecimento e a socializar esse conhecimento com a comunidade. Então levei uma biografia curta de cinco cientistas: Albert Einstein, Stephen Hawking, Nise da Silveira, Milton Santos e Duília de Melo. Quis comtemplar na minha amostra muIheres, homens, negros, brancos, pessoas vivas e já falecidas e que tivessem desenvolvidos pesquisas em diferentes campos do saber. Aí eu apresentei três características comuns de todos os cientistas: curiosidade, observação e registro. Disse que para ser um cientista é preciso ter curiosidade, se dedicar em observar aquilo que você está pesquisando e produzir um registro de suas observações. Depois disso pedi que eles escolhessem um dos cientistas apresentados e fizessem uma 
pesquisa em casa. Para minha surpresa a maioria não escolheu Albert Einstein ou Stephen Hawking, mas tiveram a curiosidade de pesquisar os outros nomes que eu levei! Achei o máximo isso, eles reconhecendo o Milton Santos e identificando ele como um cientista que estudava geografia social! (Professora Iniciante).

As reflexões e desdobramentos que a provocação da orientadora fizeram na professora iniciante nos fazem vislumbrar formas de transpor a distância que separa a universidade e a escola, sobretudo quando os professores encontram formas de narrar/compartilhar suas história, ou ainda biografar suas experiências (DELORY-MOMBERGER, 2012, 2014), em espaços acadêmicos. Cabe destacar que, como sinalizado na introdução desse texto, todo trabalho de investigação apresenta vestígios biográficos.

Dessa forma, reconhecemos que a possibilidade de fazer do espaço do grupo de pesquisa um local de troca e reflexão sobre a educação básica só foi possível porque esse grupo como um todo, incluindo seus membros e sua orientadora/coordenadora, está fortemente engajado na defesa de uma escola pública, gratuita, laica e comprometida com a questão da distribuição igualitária do conhecimento para todos. Talvez se essa não fosse uma preocupação mobilizadora do grupo já há muito tempo a escuta e acolhida dos relatos dessa professora iniciante não teriam sido da mesma forma e na mesma proporção, e este texto não teria sido possível.

Em meio aos dilemas e dúvidas e da constante sensação de "ter que inventar a roda" e "descobrir" quais conteúdos deveriam ser ensinados a professora iniciante, ao ser interpelada/provocada a pensar suas prática docente na articulação entre conhecimento escolar e conhecimento científico, conseguiu, pelo menos por um momento, dar conta de suas preocupações "práticas" sobre o que fazer em sala de aula e elaborar um plano de atividade que, ainda que não explicitamente, expressava uma discussão sobre currículo, sobre seleção e distribuição de conteúdos e sobre produção de conhecimento escolar no diálogo com o conhecimento científico (MONTEIRO, 2001; GABRIEL, 2014).

Os desdobramentos da provocação sofrida pela professora iniciante nos fazem problematizar a relação entre ser professores/as da educação básica e pesquisadores/ as científicos, que não precisam ser, necessariamente, relações opostas ou conflituosas. Ainda que as duas carreiras tenham suas especificidades e contornos próprios é possível vislumbrar, por meio da dupla inserção dessa professora iniciante, uma relação entre esses dois universos de profissionais da educação profícua e cheia de possibilidades de trocas positivas, que influencia não apenas o fazer investigativo e científico, mas mobiliza e produz desdobramentos práticos em sala de aula da educação básica.

A experiência dessa professora iniciante, apesar de há muito tempo desejada e intensamente vivida, foi breve. Com três meses de magistério ela precisou rescindir seu contrato na escola porque conseguiu a bolsa do doutorado, e para receber o benefício financeiro não podia estar trabalhando. Mais uma vez ela teve que escolher entre a carreira docente na educação básica e sua formação em pesquisa acadêmica. 
Então, gente, tenho um informe para dar: saiu minha bolsa do doutorado! Mas para poder receber a bolsa não posso estar trabalhando... então eu vou ter que sair da escola. Mesmo querendo ficar na escola eu sei que essa é a melhor opção agora para minha formação. A forma que eu me consolei de mais uma vez adiar a construção de minha carreira como professora é que ao me dedicar ao doutorado eu estou me preparando para ser uma professora melhor no futuro. Quando fui me despedir das crianças foi isso que eu falei para elas. Que eu precisava deixar de ser professora nesse momento para poder me dedicar em ser cientista. Lembrei com elas as nossas aulas sobre ser cientista, fazer pesquisa, observar e registrar. Mas eu disse para eles que isso era uma forma de eu me preparar para ser uma professora melhor. Eles entenderam e no meu último dia em sala de aula recebi um monte de bilhetes dos meus alunos, um deles dizia: "Tia, estou triste porque você está indo embora, mas também estou feliz porque você vai ser cientista. Querida professora, te amo. Seja uma boa cientista!" (Professora Iniciante).

Apesar de apontarmos para as possibilidades positivas de articulação entre a universidade e a escola, no que diz respeito a escuta e acolhida do dilemas que atravessam os professores iniciantes, trazemos também para o debate a questão que diz respeito às escolhas que marcam e conduzem nossas trajetórias profissionais como professores. Ao optar inicialmente pela formação acadêmica, adiandoo ingresso na carreira docente a professora iniciante fez uma escolha de trajetória que, segundo ela, não produziu nela efeitos de identificação como professora. Foi apenas quando ingressou na escola e teve, então, a chancela institucional (NÓVOA, 1995), que ela se sentiu parte de um corpo profissional. No entanto, sua breve experiência como professora iniciante teve que ser interrompida não apenas para que ela pudesse ser doutoranda/doutora em educação, mas para que ela pudesse, então, ser uma "professora melhor", articulando, assim como colocado no bilhete de despedida dos seus alunos, o "ser professora" com "ser uma boa cientista."

\section{ARREMATES PROVISÓRIOS}

Maurice Tardif (2014), ao se debruçar sobre a questão dos saberes docentes, afirma que os saberes que compõem a profissionalidade docente não são aqueles exclusivamente adquiridos nos cursos de formação de professores, mas sim um amálgama de saberes oriundos de diferentes fontes. Assim, os saberes docentes são constituídos por saberes disciplinares, saberes curriculares, saberes da formação profissionais e saberes experienciais, que são aqueles que os professores desenvolvem com base no seu trabalho cotidiano e nas suas experiências profissionais.

No processo de identificação docente da professora iniciante apresentada neste texto é possível assinalarmos que foi apenas quando ela acessou a dimensão dos saberes experienciais, a partir de sua inserção em sala de aula, que ela pode então se reconhecer como professora. Mesmo já habilitada formalmente com um diploma de ensino superior que atestava que ela havia cumprido os requisitos acadêmicos para atuar como professora, 
inclusive no que diz respeito à aquisição de saberes disciplinares, saberes curriculares, e saberes da formação profissionais, não foram esses saberes, no seu caso específico, que a fizeram tornar-se professora. Para alcançar essa identificação foi preciso que a experiência de sala de aula fosse uma realidade para ela.

A articulação entre "escola" e "tornar-se professor" também é sinalizada por SENNA DIAS (2018) ao investigar como professores em formação no curso de Pedagogia se reconhecem ou não como futuros professores. Uma das conclusões desta autora, que vem a ser a professora iniciante cujos relatos possibilitaram a escrita desse artigo, é que os estudantes do curso de Pedagogia que apresentam maior identificação com a profissão docente e que desejam investir em uma carreira futura como professores são aqueles que tiveram contato mais prolongado e duradouro com a instituição escolar durante sua formação acadêmica.

Assim, nos juntamos aqui ao grupo dos que assumem a escola como lócus privilegiado na construção dos processos de subjetivação/identificação docente. Mas, ao mesmo tempo, reconhecemos que outros espaços de formação, como grupos de pesquisa acadêmica na universidade, podem ser também lugar de compartilhamento e produção dessa mesma subjetividade, funcionando como um entre-lugar entre a universidade e a escola e auxiliando na superação dos binarismos do campo educacional que tendem a colocar em oposição a pesquisa acadêmica e a docência na educação básica. Dessa forma, o olhar que temos procurado dar para a escola em nossas pesquisas e discussões se aproxima da provocação de Larrosa e Venceslao (2017, p. 114)

(...) um olhar amoroso tanto para a escola, como para a tradição pedagógica: algo que não é fácil nesses tempos em que está instalado o tópico da "crítica da escola tradicional", em que a própria escola é declarada todos os dias como sendo enfadonha, obsoleta, ineficaz, inútil, anacrônica, etc., etc., etc., e no qual aos jovens aprendizes de educadores só se ensina a ver a escola como algo que tem que mudar e se apresenta a tradição pedagógica como um museu de antiguidades.

Mobilizadas, porém, por esse "olhar amoroso" para a escola é que nos lançamos nessa escrita em dupla autoria em que orientadora e orientanda afetaram-se mutuamente a partir do compartilhamento de suas experiências biográficas e vivenciaram um processo compartilhado de subjetivação/identificação docente. Finalizamos assim esse texto tomando de empréstimo as palavras de Delory-Momberger (2012), que nos serviu de aporte teórico na discussão sobre identidade e sujeito biográfico e que nos lembra que o fazer pesquisa é essa troca humana na busca de compreensão e conhecimento.

Todos os protocolos metodológicos (...) têm, ao mesmo tempo, seu alcance e seus limites. Qualquer que seja seu grau de tecnicidade e de sofisticação (por vezes, muito elevado), sua utilização não acontece sem uma dose de "bricolagem" (no sentido em que Lévi-Strauss usa esse termo). E essa bricolagem é, afinal, o signo e a garantia de uma busca "humana" de compreensão e de conhecimento empreendida 
por seres singulares e endereçada a outros seres singulares. Essa ambição, talvez louca, de atingir as próprias fontes e os modos de efetuação da singularidade individual só pode trilhar os caminhos de uma "hermenêutica da relação" em que o pesquisador empreende, ele também, um "trabalho do sujeito", tanto quanto o autor do relato, e em interação com ele. Talvez o pesquisador, mesmo quando "armado" de seus modelos e grades, não faça e não possa fazer nada a não ser "contar" por sua vez aquilo que lhe "contam" os relatos dos outros. É pouco e é muito, é o preço de uma ciência "humana" - e é seu tesouro. (DELORY-MOMBERGER, 2012, p. 535).. 


\section{REFERÊNCIAS}

AGUIAR, M. A. da S. et al. Diretrizes curriculares do curso de pedagogia no Brasil: disputas de projetos no campo da formação do profissional da educação. Educação e Sociedade. Campinas, v. 27, n. 96, p. 819-842, 2006. Disponível em http://www.scielo.br/scielo.php?pi$\mathrm{d}=$ S0101-73302006000300010\&script=sci_abstract\&tlng=pt. Acesso em: 7 jul. 2018.

BIESTA, G. Para além da aprendizagem: educação democrática para um futuro humano. Belo Horizonte: Editora Autêntica, 2013.

BRASIL. Lei n 9.394, de 20 de dezembro de 1996. Estabelece as diretrizes e bases da educação nacional. Diário Oficial da União, Brasília, DF, 23 dez. 1996.

BRASIL. Resolução CNE/CP n 1, de 15 de maio de 2006. Institui Diretrizes Curriculares Nacionais para o Curso de Graduação em Pedagogia, licenciatura. Diário Oficial da União: seção 1, Brasília, DF, p. 11, 16 maio 2006.

CAPRIATI, A. J. El método biográfico: una tradición que se renueva: apuntes sobre seus usos y desafios. In: BRAGANÇA, I. F. de S.; ABRAHÃO, M. H. M. B.; FERREIRA, M. S. (org.). Perspectivas epistêmico-metodológicas da pesquisa (auto)biográfica. Curtiba: Editora CRV, 2016. p. 219-234.

CRUZ, G. B. da; AROSA, A. A formação do pedagogo docente no curso de pedagogia. Revista Educação e Cultura Contemporânea, v. 11, n. 26, p. 30-68, 2014. Disponível em: http://periodicos. estacio.br/index.php/reeduc/article/viewArticle/1124. Acesso em: 7 jul. 2018.

CRUZ, G. B. da. Curso de pedagogia no Brasil: história e formação com pedagogos primordiais. Rio de Janeiro: Wak Editora, 2011.

DELORY-MOMBERGER, C. A pesquisa biográfica ou a construção compartilhada de um saber do singular. Revista Brasileira de Pesquisa (Auto)biográfica, v. 1, n. 1, 2016, p. 133-147.

DELORY-MOMBERGER, C. Abordagens metodológicas na pesquisa biográfica. Revista Brasileira de Educação, Rio de Janeiro, v. 17, n. 51, p. 523-536, set./dez. 2012. Disponível em: http://www. scielo.br/scielo.php?script=sci_arttext\&pid=S1413-24782012000300002\&lng=en\&nrm=iso. Acesso em: 15 jun. 2018.

DELORY-MOMBERGER, C. Experiencia y formación: biografización, biograficidad y heterobiografía. Revista Mexicana de Investigación Educativa, México, v. 19, n. 62, 2014. Disponível em: http:// www.scielo.org.mx/scielo.php?script=sci_arttext\&pid=S1405-66662014000300003\&lng=es\&nrm=iso. Acesso em: 15 jun. 2018.

DELORY-MOMBERGER, C. Fundamentos epistemológicos da pesquisa: biográfica em educação. Educação em Revista, Belo Horizonte, v. 27, n. 1, p. 333-346, 2011. Disponível em: http://www. scielo.br/scielo.php?script=sci_arttext\&pid=S0102-46982011000100015\&lng=en\&nrm=iso. Acesso em: 15 jun. 2018.

FRANCO, M. A. do R. S. Pedagogia e prática docente. São Paulo: Cortez, 2012. 
GABRIEL, C. T. Conhecimento científico e currículo: anotações sobre uma articulação impossível e necessária. Revista Teias, Rio de Janeiro, v. 14, n. 33, p. 44-57, 2013. Disponível em: http://www.e-publicacoes.uerj.br/index.php/revistateias/article/view/24364. Acesso em: 30 nov. 2017.

GABRIEL, C. T. Didática, currículo, docência: articulações em torno do significante conhecimento escolar. In: CRUZ, G. B. da et al. (org.). Ensino de didática: entre recorrentes e urgentes questões. Rio de Janeiro: Quartet: FAPERJ, 2014. p. 171-196.

GABRIEL, C. T. Docência, demanda e conhecimento escolar: articulações em tempos de crise. Currículo sem Fronteiras, Rio de Janeiro, v. 15, n. 2, p. 425-444, 2015. Disponível em: http://www. curriculosemfronteiras.org/vol15iss2articles/gabriel.pdf. Acesso em: 30 nov. 2017.

GATTI, B.; BARRETO, E. S. de S. Professores do Brasil: impasses e desafios. Brasília, DF: UNESCO, 2009.

HUBERMAN, M. O ciclo de vida profissional de professores. In: NÓVOA, A. (org.). Vida de professores. Porto-PT: Porto Editora, 1992. p. 31-62.

INGERSOLL, R.; STRONG, M. The impact of induction and mentoring programs for beginning teachers: a critical review of the research. Review of Educational Research, v. 81, n. 2, p. 201-233, July 2011.

LACLAU, E. Emancipação e diferença. Rio de Janeiro: EdUERJ, 2011.

LAPO, F. R.; BUENO, B. O. O abandono do magistério: vínculos e rupturas com trabalho docente. Psicologia USP, São Paulo, v. 13, n. 2, p. 243-276, 2002. Disponível em: http://www.scielo. br/scielo.php?script=sci_arttext\&pid=S0103-65642002000200014\&Ing=en\&nrm=iso. Acesso em: 6 set. 2017.

LARROSA, J.; VENCESLAO, M. Um povo capaz de skholé: elogio das Missões Pedagógicas da II República Espanhola. In: LARROSA, J. (org.). Elogio da escola. Belo Horizonte: Autêntica Editora, 2017. p. 113-146.

LIBÂNEO, J. C. Diretrizes curriculares da pedagogia: imprecisões teóricas e concepção estreita da formação profissional de educadores. Educação e Sociedade, v. 27, n. 96, p. 843-876, 2006. Disponível em: http://www.scielo.br/scielo.php?pid=S0101-73302006000300011\&script=sci_abstract\&tlng=pt. Acesso em: 7 jul. 2018.

LIBÂNEO, J. C. Licenciatura em pedagogia: a ausência dos conteúdos específicos do ensino fundamental. In: GATTI, B. A. et al. (org.). Por uma Política Nacional de formação de professores. São Paulo: UNESP, 2013. p. 73-94.

LOPES, A. C.; MACEDO, E. Teorias de currículo. São Paulo: Cortez, 2011.

LOPES, A. C. Teorias pós-críticas, política e currículo. Educação, Sociedade \& Culturas, Porto-PT, n. 39, p. 7-23, 2013. Disponível em: https://www.fpce.up.pt/ciie/sites/default/files/02.AliceLopes. pdf. Acesso em: 10 fev. 2018. 
MABILON-BONFILS, B. De la (re) (ré) construction d'unitin"'raire de recherche ou quandl'objetimplicite "dit" de sujet. Le Sujet Dans La Cité: revue intenationale de recherche biographique. Paris: Université Paris 13 Sorbonne, n. 8, p. 167-186, nov. 2017.

MARCHART, O. EI pensamiento político posfundacional: la diferencia política en Nancy, Lefort, Badiou y Laclau. Buenos Aires: Fondo de Cultura Económica, 2009.

MONTEIRO, A. M. F. da C. Professores: entre saberes e práticas. Educação e Sociedade. Campinas, v. 22, n. 74, 2001. Disponível em: http://www.scielo.br/scielo.php?script=sci_arttext\&pi$\mathrm{d}=\mathrm{S} 0101-73302001000100008 \& \mathrm{Ing}=e n \& \mathrm{nrm}=\mathrm{iso}>$. Acesso em: 30 maio 2016.

NÓVOA, A. Currículo e docência: a pessoa, a partilha, a prudência. In: GONÇALVES, E. P.; PEREIRA, M. Z. da C.; CARVALHO, M. E. P. de. (org.). Currículo e contemporaneidade: questões emergentes. Campinas: Alínea, 2004. Disponível em: http://hdl.handle.net/10451/4816. Acesso em: 1 set. 2017.

NOVOA, A. Firmar a posição como professor, afirmar a profissão docente. Cadernos de Pesquisa, São Paulo, v. 47, n. 166, p. 1106-1133, dez. 2017. Disponível em: http://publicacoes.fcc.org.br/ojs/ index.php/cp/article/view/4843. Acesso em: 3 mar. 2018.

NÓVOA, A. O passado e o presente dos professores. In: NÓVOA, A. (org.). Profissão professor. Porto-PT: Porto Editora, 1995.

NÓVOA, A. (org.). Vida de professores. Porto-PT: Porto Editora, 1992.

PASSEGGI, M. da C.; CUNHA, L. M. da. Narrativas autobiográficas: a imersão no processo de autoria. In: VICENTINI, P. P.; SOUZA, E. C. de; PASSEGGI, M. da C. (org.). Pesquisa (auto)biográfica: questões de ensino e formação. Curitiba: Editora CRV, 2013. p. 43-58.

PIMENTA, S. G. et al. Os cursos de licenciatura em pedagogia: fragilidades na formação inicial do professor polivalente. In: SILVESTRE, M. A.; PINTO, U. de A. (org.). Curso de pedagogia: avanços e limites após as diretrizes curriculares nacionais. São Paulo: Cortez, 2017. p. 23-48.

PUGAS, M. C. de S. Conhecimento e docência no currículo de pedagogia: entre o pedagógico e o disciplinar. 2013. Tese (Doutorado em Educação) - Faculdade de Educação, Universidade Federal do Rio de Janeiro, Rio de Janeiro, 2013.

RAMOS, M. A.; GONÇALVES, R. E. As narrativas autobiográficas do professor como estratégia de desenvolvimento e a prática da supervisão. In: ALARCÃO, I. (org.). Formação reflexiva de professores: estratégias de supervisão. Porto: Porto Editora, 1996. p.123-150.

RETAMOZO, M. M. Construtivismo: epistemologia y metodologia em la ciências sociales. In: GARZA TOLEDO, E. de la; LEYVA, G. (ed.). Tratado de metodología de las ciências sociales: perspectivas actuales. México: FCE: UAM, 2012. p. 325-350.

SANTANA, O. A. Evasão nas licenciaturas das Universidades Federais: entre a apetência e a competência. Educação (UFSM), Santa Maria, p. 311-328, 2016. Disponível em: https://periodicos. ufsm.br/reveducacao/article/view/20199. Acesso em: 6 set. 2017.

SAVIANI, D. A pedagogia no Brasil: história e teoria. Campinas: Autores Associados, 2008. 
SCHEIBE, L.; DURLI, Z. Curso de pedagogia no Brasil: olhando o passado, compreendendo o presente. Educação em Foco, Belo Horizonte, ano 14, n. 17, p. 79-109, jul. 2011. Disponível em: http:// revista.uemg.br/index.php/educacaoemfoco/article/view/104. Acesso em: 7 jul. 2018.

SCOTT, J. W. Experiência. In: SILVA, A. L. da; SOUZA, M. C. de L.; RAMOS, T. R. O. (org.). Falas de gênero. Santa Catarina: Editora Mulheres, 1999. p. 21-55.

SENNA DIAS, B. N. de. Tornar-se professor: sentidos negociados de docência no currículo de Pedagogia da UFRJ. 2018. 170 f. Dissertação (Mestrado em Educação) - Faculdade de Educação, Universidade Federal do Rio de Janeiro, Rio de Janeiro, 2018.

SILVA, C. S. B. da. Curso de pedagogia no Brasil: história e identidade. 3 ed. Campinas: Autores Associados, 2006.

SILVA JÚNIOR, C. A. Prefácio. In: SILVESTRE, M. A.; PINTO, U. de A. (org.). Curso de pedagogia: avanços e limites após as diretrizes curriculares nacionais. São Paulo: Cortez, 2017.

SILVESTRE, M. A.; PINTO, U. de A. Apresentação. In: SILVESTRE, M. A.; PINTO, U. de A. (org.). Curso de pedagogia: avanços e limites após as diretrizes curriculares nacionais. São Paulo: Cortez, 2017.

TARDIF, M. Saberes docentes e formação profissional. Petrópolis-RJ: Editora Vozes, 2014.

ZEICHNER, K. M. Para além da divisão entre professor-pesquisador e pesquisador acadêmico. In: GERALDI, C.; FIORENTINI, D.; PEREIRA, E. M. de A. (org.). Cartografias do trabalho docente: professor(a)-pesquisador(a). Campinas-SP: Mercado das Letras, 1998. p. 207-236. 